\title{
Book Review: Alter(n) als Soziale und Kulturelle Praxis. Ordnungen - Beziehungen - Materialitäten
}

\author{
Monika Urban* \\ Institute for Public Health and Nursing, University of Bremen, Bremen, Germany
}

Keywords: book review, doing age, ethnography, culture studies, material culture studies

\section{A Book Review on}

\author{
Alter(n) als Soziale und Kulturelle Praxis. Ordnungen - Beziehungen - Materialitäten \\ Cordula Endter and Sabine Kienitz (Bielefeld: Transcript), 2017, 368 pages.
}

Aging studies have made their praxeological turn. In the recently published anthology titled "Aging as Social and Cultural Praxis. Orders - Relationships - Materiality" aging is not analyzed as a biological process associated with deteriorating health, but rather as a social practice. This comprehensive volume, edited by Cordula Endter and Sabine Kienitz, theoretically grasped aging as shaped by, and performed within, a social and cultural order and as being interwoven within human and non-human (as things or architecture) relationships. Therewith, the scope of the book is to theoretically and empirically grasp, how humans and non-humans age. Thereby, this is identified as a question of doing age.

This volume emerged from an interdisciplinary conference held at the Institute of Ethnology and Cultural Anthropology at the University of Hamburg in 2015. The 22 esteemed authors provide perspectives on disciplines including ethnology, sociology of aging, cultural studies, discourse studies, historiography and gerontology. This volume is subdivided into three thematic subsections: aging with respect to orders, as a matter of relationships, and the material side of aging. The contributions of each subsection reflect perspectives of the different disciplines in order to present aging as multilayered and complex.

Such social-constructivist alignments of doing age correspond well with the series titled Aging Studies, published by transcript. However, unlike the series, the articles of this present anthology are primarily published in German. Notable exceptions include Amy Clotworthy, Kamilla Nortoft and Tiina Suopajärvi, all conducting ethnographical studies in Scandinavian countries, which are printed in English. While the first two researchers grapple with changing relationships in care contexts, the third raises questions on safety, accessibility, unpleasant places and changing sensory experiences in urban environments using an ethnographic walks approach. While this choice of German language might be convenient for the authors, it surely gets in the way of international recognition, which the volume definitely deserves.

Taking a closer look into the first subsection, doing age is portrayed as framed and directed by orders: Political institutionalizations such as retirement regulations and the reorganization and dismantling of the social state, are comprised of being productive, but less as determining the doing age. These factors are seen as interwoven with the hegemonic ideal of successful aging and its call for active self-management. For example Silke van Dyk and Tina Denninger focus on the practices related to the neoliberal discourses of activation and responsibilisation. Within a sociological perspective, these two authors deduce the feminization of old-age poverty. Equally the article by Irene Götz, Esther Gajek, Alexandra Rau und Petra Schweiger takes a feminist perspective 
on precarity in old age, by grasping the aging body as object of pejorative inscriptions. In turn the articles by Rebecca Niederhauser and Anna Richter address the ambivalence of derogatory inscriptions of old age, the failing recognition of the elderly's biographical achievements and in turn on a selfperception, which resists such categorizations. Moreover, an interesting and well written article is penned by Gerrit Herlyn, who examines doing biography in the setting of early Punk and Gothic subcultural affinities. Eventually, as a logical deduction of this subsection, the article of Harm Peer Zimmermann pleads for a de-thematization of aging: He suggests disempowering aging by referring to influential texts of the French philosophers Sartre, de Beauvoir and Améry.

The second subsection follows the footsteps of Bruno Latour and Julia Twigg. The authors here choose ethnographic methodologies to analyze the relationship changes caused by increasing physical and psychological vulnerability. For this purpose, they examined everyday life practice, lifestyles, and biographical projects. By referring to the hegemonic anti-aging ideal, Larissa Pfaller and Mark Schweda thematise the increasing bio-medicalization of, and responsibilisation for, age and aging. They exemplify not just the effects but also the margins for maneuver that the elderly develop in day to day practices and narrations. Furthermore in this subsection, Barbara Ratzenböck conducts ethnographic walking interviews to explore the media practices of older women. She identifies in which way media practices are gendered and shaped by class and cultural contexts.

Finally, in the last subsection the material side of aging is addressed. Five unique articles outline dialectic dynamics between things and humans in the aging process by asking questions as: How people age by applying things, e.g., wearing clothing? How things become relevant in aging processes? For instance Esther Gajek centers on the body as a space of social and cultural inscriptions. Based on the results of a student project, she reconstructs age-related motivations and gendered do-nots in dressing habits. Anamaria Depner and Carolin Kollewe, both following the material culture study, observe the effects of everyday objects, such as handbags in dementia care and Ambient Assisted Living (AAL) Technologies in in-house care settings. Last but not least, the editors of the anthology outline the complex interrelationship of aging and materiality by focusing on three factors: (1) the processes artifacts undergo whilst aging, using the example of plastics, (2) how clothing define the age of humans, due to the outdating of styles, and (3) how aging and its ideals change due to artifacts: AAL is shown to empower people with disabilities to live autonomously and independently but therewith those practices using AAL stabilize the ideals of such a successful aging.

In conclusion, this volume maps perfectly the topics that the European cultural aging studies are currently involved in. The overall underlying concept of age as doing age is highly convincing. Most authors committed to using an ethnographic methodology. However, some articles-such as that by Maria Keil on the cultural history of the nursing bed or that one by Anna Symanczyk on sound design for an older target group-offer a refreshing change by using a historiographic approach as well as media science typologies. The editors did well by selecting articles which reflect the interrelationship of discourses, performativity's and materiality's. This absolutely recommendable volume turns out well in opposition to that neoliberal project of responsibilisation for successful aging, while this same political project has pauperized old age through the reduction of fiscal expenditure.

\section{AUTHOR CONTRIBUTIONS}

The author confirms being the sole contributor of this work and approved it for publication.

Conflict of Interest Statement: The author declares that the research was conducted in the absence of any commercial or financial relationships that could be construed as a potential conflict of interest.

Copyright (c) 2018 Urban. This is an open-access article distributed under the terms of the Creative Commons Attribution License (CC BY). The use, distribution or reproduction in other forums is permitted, provided the original author(s) and the copyright owner are credited and that the original publication in this journal is cited, in accordance with accepted academic practice. No use, distribution or reproduction is permitted which does not comply with these terms. 